\title{
Fatigue in patients with epilepsy and its association with depression and sleep quality
}

Fadiga em pacientes com epilepsia e sua associação com depressão e qualidade do sono

Gisele S. M. Leite Neves', Marleide da Mota Gomes²

\begin{abstract}
Objective: It was to evaluate the relationships between fatigue and excessive daytime sleepiness, sleep quality, depression and anxiety. Methods: This was a cross-sectional study on 98 unselected adult patients with epilepsy (PWE) at a tertiary center. It used clinicalsociodemographic characteristics, fatigue measured by the SF-36 vitality subscale (VsSF-36) and the Epworth Sleepiness Scale, Pittsburgh Sleep Quality Index and Beck Depression and Anxiety Inventories. Results: We observed that our patients presented vitality or fatigue similar to drivers with chronic headaches evaluated in the same city. Fatigue was related to depression, anxiety and sleep quality, but not to daytime sleepiness. A multiple linear regression analysis was conducted and we observed that fatigue was independently correlated with depression and quality of sleep. However, no significant difference was observed regarding seizure frequency or number of antiepileptic drugs. Conclusion: Fatigue needs to be studied more in PWE, and its risk factors need to be controlled, along with sleep quality and psychiatric disorders.
\end{abstract}

Key words: epilepsy, fatigue, depression, anxiety, sleep disorders.

\section{RESUMO}

Objetivo: Foi avaliar a relação entre fadiga e sonolência excessiva diurna, qualidade de sono, depressão e ansiedade. Métodos: Estudo transversal com 98 pacientes adultos com epilepsia não selecionados (PCE) em centro terciário, considerando: características clínico-sociodemográficas, fadiga pela vitalidade do SF-36 (VsSF-36), Escala de Sonolência de Epworth, Índice de Qualidade de Sono de Pittsburgh, Inventários de Depressão e Ansiedade de Beck. Resultados: Nossos pacientes têm vitalidade/fadiga similar àquela dos motoristas com cefaleia crônica avaliados na mesma cidade. A fadiga foi relacionada à depressão, ansiedade e qualidade do sono, mas não à sonolência excessiva diurna. Após análise de regressão linear múltipla, a fadiga foi independentemente correlacionada à depressão e à qualidade do sono, não havendo diferença significativa em relação à frequência de crises nem ao número de drogas antiepilépticas. Conclusões: A fadiga deve ser mais estudada em PCE, e seus fatores de risco, como a qualidade do sono e os transtornos psiquiátricos, precisam ser controlados.

Palavras-Chave: epilepsia, fadiga, depressão, ansiedade, transtornos do sono.

Fatigue is often seen in medical practice, but it is not examined adequately, and even less so among patients with epilepsy ${ }^{1}$. It is difficult to define, since it is a subjective experience and, hence, difficult to measure ${ }^{2}$.

Hernandez-Ronquillo et al. ${ }^{1}$ proposed that fatigue can be defined as extreme and persistent tiredness, weakness or exhaustion that can be mental, physical or both. It is a frequent complaint among patients with epilepsy, in spite of being insufficiently examined $^{1,3-7}$. Hernandez-Ronquillo et al. ${ }^{1}$ indicated that little is known about the severity, impact and phenomenology of fatigue among people with epilepsy. Tellez-Zenteno, Matijevic and Wiebe. ${ }^{4}$ demonstrated that epilepsy presented a statistically significant association with chronic fatigue, in addition to associations with asthma, back problems, heart disease, fibromyalgia and stomach/intestinal ulcers. The same authors ${ }^{4}$ demonstrated that chronic fatigue was four times more frequent in patients with epilepsy than in the general Canadian population, and that fatigue was an important feature of other health conditions, including cancer and other neurological diseases such as multiple sclerosis and Parkinson's disease.

However, the term fatigue is often used interchangeably with excessive daytime sleepiness ${ }^{8}$, defined as the inability to stay awake and alert during the major waking periods of the

${ }^{1}$ Neurologist, Institute of Neurology, Federal University of Rio de Janeiro (UFRJ), Rio de Janeiro RJ, Brazil;

${ }^{2}$ Associate Professor, School of Medicine, Institute of Neurology, UFRJ, Rio de Janeiro RJ, Brazil.

Correspondence: Gisele S. M. Leite Neves; Instituto de Neurologia Deolindo Couto, Universidade Federal do Rio de Janeiro (UFRJ); Avenida Venceslau Braz 95;

22290-140 Rio de Janeiro RJ - Brasil; E-mail:gsmlneves@gmail.com.br

Conflict of interest: There is no conflict of interest to declare.

Received 29 October 2012; Received in final form 14 March 2013; Accepted 21 March 2013. 
day, thus resulting in unintended lapses into drowsiness or sleep (ICDS-2 $)^{9}$. Consequently, fatigue has been largely overlooked in assessing and managing patients suffering from epilepsy. This may, in part, be due to the fact that fatigue is typically not considered to be a paramount feature of epilepsy ${ }^{1}$.

Several specific instruments are available for measuring fatigue, as well as fatigue subscales within comprehensive measurements of quality of life, such as the vitality component of the Short Form $36(\mathrm{SF}-36)^{10}$. Mead et al. ${ }^{11}$ used the latter instrument to evaluate associations presented by post-stroke fatigue and the influence of this factor on survival. Concerning epilepsy, Hernandez-Roquillo et al. ${ }^{1}$ validated three scales for clinical use: Fatigue Symptom Inventory (FSI), Fatigue Assessment Instrument (FAI) and Fatigue Severity Scale (FSS). Regarding studies on the relationship between fatigue and excessive daytime sleepiness and quality of sleep, there are none among patients with epilepsy, but such studies have been produced in relation to multiple sclerosis ${ }^{12}$, Charcot-Marie-Tooth disease $\mathrm{e}^{13}$ and migraine $\mathrm{e}^{14}$.

The main aim of the present study was to evaluate fatigue and to investigate possible relationships with excessive daytime sleepiness, quality of sleep, depression and some epilepsy characteristics among patients with epilepsy.

\section{METHOD}

A cross-sectional study based on 98 unselected patients at the outpatient clinic of the Neurological Institute, Federal University of Rio de Janeiro, Brazil, was conducted over a one-year period. The patients were men and women aged 18 to 65 years who had been diagnosed with epilepsy (focal or generalized) in accordance with the criteria of the International League Against Epilepsy. The patients gave their informed consent, and the study was approved by the local Ethics Committee.

The patients completed a self-administered questionnaire. Two subjects were excluded because of missing data in the Medical Outcomes Study 36-Item Short Form Health Survey $\left(\right.$ MOS SF-36) ${ }^{10}$. Only patients on a stable antiepileptic drug regimen were included (no changes over the last four weeks). Patients with other active neurological diseases were excluded.

Fatigue, subjective quality of sleep, daytime sleepiness, depression and anxiety were evaluated using the following self-applied questionnaires: MOS SF-36 ${ }^{10}$, Pittsburgh Sleep Quality Index (PSQI) ${ }^{15}$, Epworth Sleepiness Scale (ESS) ${ }^{15}$, Beck Depression Inventory (BDI) ${ }^{16,17}$ and Beck Anxiety Inventory $(\mathrm{BAI})^{16,17}$, respectively. Information on age, gender, comorbidities, seizure frequency, number of antiepileptic drugs and seizure type was also collected.

Fatigue was evaluated by means of the vitality subscale (mental health component) of the MOS SF-36 (VsSF36). The VsSF-36 assesses energy and fatigue in order to capture differences in subjective well-being (four questions), along with questions relating to depression and anxiety. This subscale has been also used on people with chronic obstructive pulmonary disease, Sjögren's syndrome, chronic fatigue syndrome and systemic lupus erythematosus ${ }^{2}$. Patients grade their responses on a five-point scale ranging from none of the time to all of the time. The standardized scores range from 0 to 100, with lower scores indicating lower vitality ( fatigue).

The PSQI comprises 19 questions that are combined to form seven components, each ranging from 0 to $3^{15}$. These seven components combine to form an overall score that ranges from 0 to 21 , such that 0 indicates no difficulty and 21 indicates severe difficulty regarding sleep quality.

The BDI is one of the most widely used instruments for measuring the severity of depression, and the BAI is an instrument for measuring the severity of anxiety ${ }^{15,16}$. The BDI is composed of 21 questions on how the subject has been feeling during the past week, and each question presents at least four possible answer choices. The BAI has the same structure, but with regard to how the subject has been feeling during the past week in terms of common symptoms of anxiety.

The ESS is a scale used to determine the level of daytime sleepiness. It asks subjects to rate their likelihood of falling asleep on a scale of increasing probability from 0 to 3, in eight different situations that most people engage in during their daily lives ${ }^{15}$.

The comorbidities studied were arterial hypertension, smoking and obesity (BMI $\geq 30)$, and the first two of these were considered positive if the patient answered "yes" in the questionnaire.

For comparison purposes, our data regarding fatigue (VsSF-36) was compared with that of drivers with and without chronic headaches in Rio de Janeiro ${ }^{18}$.

Spearman's rank correlation coefficient was used. Two-tailed tests were performed, and the significance level was set at 0.05. The software package used was SPSS 11.01. A multivariate analysis was performed by means of multiple linear regression to assess the influence of the indicators on fatigue (evaluated by VsSF-36). The process of variable selection was stepwise forward, at the level of $5 \%$, which selected the smallest subgroup of independent variables that influenced fatigue.

\section{RESULTS}

The main characteristics of the studied population are presented in Table 1. Most patients presented generalized seizures and had experienced fewer than four seizures during the past year. They showed a wider distribution of fatigue scores measured using VsSF-36 than shown by professional drivers in the same city with chronic headaches ${ }^{18}$. However, this difference was not statistically significant regarding our studied population with epilepsy versus drives with chronic headache 
(mean standard deviation $\mathrm{N}$ ): 60.25/25.40/98 versus $59.8 / 13.4 / 31 ; p>0.9249$. It was noticeable that the drivers with chronic headaches had lower vitality scores than the drivers who did not present these symptoms: $59.8 / 13.4 / 31$ versus $66.7 / 9.5 / 24 ; \mathrm{p}=0.04^{18}$.

Regarding the influence of comorbidities on vitality (arterial hypertension, obesity and smoking), no statistically significant association was observed. Table 2 presents the correlation between fatigue and clinical variables. We observed that fatigue presented moderate correlations with depression, anxiety and quality of sleep, but not with excessive daytime sleepiness. We found that depression and quality of sleep were independently predictive of fatigue (Table 3).

\section{DISCUSSION}

Our patients showed fatigue/vitality that was similar to that of drivers with chronic headaches ${ }^{18}$. It should be noted that Hernandez-Ronquillo et al. ${ }^{1}$ mentioned that their fatigue scores were comparable to those of patients presenting other neurological conditions, in spite of being noteworthy in patients with multiple sclerosis and Parkinson's disease. However, no clear relationship between the physical comorbidities studied and fatigue was demonstrated, even though a relationship between comorbidities and fatigue has been seen in the general population ${ }^{19}$. We observed that only depression and sleep quality were independently related to fatigue. According to several authors, in patients both with and without epilepsy, fatigue may be associated with depression ${ }^{3,5-7}$ and is related to lower quality of life in some domains ${ }^{3,7}$.

In the present study, we did not observe any significant relationships between fatigue, frequency of seizures and number of epileptic drugs, in contrast to the study by Hernandez-Ronquillo et al. ${ }^{1}$, but in agreement with the report by Hamelin, Kahane and Vercueil ${ }^{7}$. Our findings demonstrate the importance of low sleep quality and underdiagnosed psychiatric symptoms in these patients, with regard to improving seizure management. In a study on patients with multiple sclerosis, fatigue was associated with clinical disability and sleep quality, but not with excessive daytime sleepiness ${ }^{12}$. Those authors concluded that fatigue was best explained by clinical disability and poor sleep quality, a finding that was similar to what was observed in the present study ${ }^{12}$. In another study with a similar aim, patients with Charcot-Marie Tooth (CMT) were compared with a control group. The CMT patients reported significantly higher fatigue, greater extent and prevalence of daytime sleepiness and worse sleep quality ${ }^{13}$. However, a paper on migraine patients found that they presented worse quality of sleep, and that fatigue and daytime sleepiness were
Table 1. Patient characteristics.

\begin{tabular}{lc} 
Variables & $\mathrm{n}=98$ \\
\hline Gender (M/F) & $59 / 39$ \\
Age & $39.00 ; 39.74 \pm 12.25$ \\
Seizure type (focal/generalized) & $37 / 61$ \\
Seizure frequency/year $(<4 / \geq 4)$ & $36 / 62$ \\
Number of antiepileptic drugs $(<2 / \geq 2)$ & $47 / 51$ \\
Depression & $8.00 ; 12.3 \pm 11.60$ \\
Anxiety & $9.00 ; 9.43 \pm 11.33$ \\
Sleep quality & $6.00 ; 6.66 \pm 4.33$ \\
Fatigue & $60.00 ; 60.25 \pm 25.40$ \\
Excessive daytime sleepiness & $10.00 ; 10.20 \pm 5.46$ \\
\hline
\end{tabular}

Values are shown as number of patients or as the median and mean \pm standard deviation.

Table 2. Correlations between fatigue and clinical variables.

\begin{tabular}{lcc}
\multirow{2}{*}{ Variables } & \multicolumn{2}{c}{ VsSF-36 index } \\
\cline { 2 - 3 } & $\mathrm{r}_{\mathrm{s}}$ & $\mathrm{p}$-value \\
\hline Age & -0.191 & 0.59 \\
Seizure frequency/year & -0.052 & 0.61 \\
Depression & -0.660 & $<0.0001^{\star *}$ \\
Anxiety & -0.55 & $<0.0001^{\star *}$ \\
Quality of sleep & -0.636 & $0.002^{\star}$ \\
Excessive daytime sleepiness & -0.36 & 0.72 \\
\hline
\end{tabular}

Spearman's rank correlation coefficient or Spearman's rho; *Correlation is significant at the 0.05 level (two-tailed test); ${ }^{*}$ Correlation is significant at the 0.01 level (two-tailed test); VsSF-36: vitality subscale short form 36.

Table 3. Multiple linear regression.

\begin{tabular}{lcccc} 
Model & Coefficient & Standard error & $\mathrm{p}$-value & $\mathbf{R}^{2}$ \\
\hline 1 Depression & -1.34 & 0,18 & $<0.0001$ & 0.37 \\
2 Depression & -0.93 & 0.189 & $<0.0001$ & 0.48 \\
sleep quality & & & & \\
\hline
\end{tabular}

Dependent variable: fatigue; $\mathrm{R}^{2}=$ squared multiple correlation coefficient.

more prominent in patients than in controls, but the differences did not reach the level of statistical significance ${ }^{14}$.

Building on our study, we propose that different types of comparison groups should be included in future studies, including healthy controls, and that other, more fatigue-specific measurement scales, should be used, such as those proposed by Hernandez-Ronquillo et al. ${ }^{1}$ and Whitehead ${ }^{2}$. We also suggest that the relationship between the subjective complaints studied here and sleep structure assessed using polysomnography should be investigated, in an attempt to identify interactions between nocturnal seizures, sleep stages, interictal epileptiform activity and fatigue.

In conclusion, little knowledge is available regarding the relationships between the fatigue phenomenon and epilepsy, thus indicating that further studies are needed. The present results emphasize the importance of screening for sleep quality and comorbidities among patients with epilepsy.

Therapeutic interventions relating to fatigue, psychiatric comorbidities and sleep assessment, in addition to clinical evaluations, appear to provide a major breakthrough in treatments for patients with epilepsy. 
1. Hernandez-Ronquillo L, Moien-Afshari F, KnoxK, BritzJ, Tellez-Zenteno JF. How to measure fatigue in epilepsy? The validation of three scales for clinical use. Epilepsy Res 2011;95:119-129.

2. Whitehead L. The measurement of fatigue in chronic illness: a systematic review of unidimensional and multidimensional fatigue measures. J Pain Symptom Manage 2009;37:107-128.

3. Ettinger AB, Weisbrot DM, Krupp LB. Fatigue and depression in epilepsy. J Epilepsy 1998;11:105-109

4. Tellez-Zenteno JF, Matijevic LM, Wiebe S. Somatic comorbidity of epilepsy in the general population in Canada. Epilepsia 2005;46:1955-1962.

5. Soyuer F, Erdoğan F, Senol V, Arman F. The relationship between fatigue and depression, and event-related potentials in epileptics. Epilepsy Behav 2006;8:581-587.

6. Senol V, Soyuer F, Arman F, Oztyrk A. Influence of fatigue, depression, and demographic, socioeconomic, and clinical variables on quality of life in patients of epilepsy. Epilepsy Behav 2007;10:96-104.

7. Hamelin S, Kahane P, Vercueil L. Fatigue in epilepsy: a prospective interictal and post-ictal survey. Epilepsy Res 2010;91:153-160.

8. Neu D, Linkowski P, le Bon O. Clinical complaints of daytime sleepiness and fatigue: how to distinguish and treat them, especially when they become 'excessive 'or 'chronic'? Acta Neurol Belg 2010;110:15-25.

9. American Academy of Sleep Medicine. International Classification of Sleep Disorders. Diagnostic and coding manual. 2nd ed. Westchester, Illinois: American Academy of Sleep Medicine; 2005.

10. Ciconelli RM, Ferraz MB, Santos W, Meinão I, Quaresma MR. Tradução para a língua portuguesa e validação do questionário genérico de avaliação de qualidade de vida SF-36 (Brasil SF-36). Rev Bras Reumatol 1999;39:143-150.
11. Mead GE, Graham C, Dorman P, et al. UK Collaborators of IST. Fatigue after stroke: baseline predictors and influence on survival. Analysis of data from UK patients recruited in the International Stroke Trial. PLoS One 2011;18;6:1988.

12. Moreira NC, Damasceno RS, Medeiros CA, et al. Restless leg syndrome, sleep quality and fatigue in multiple sclerosis patients. Braz $\mathrm{J}$ Med Biol Res 2008;41:932-937.

13. Boentert M, Dziewas R, Heidbreder A, et al. Fatigue, reduced sleep quality and restless legs syndrome in Charcot-Marie-Tooth disease: a web-based survey.J Neurol 2010;257:646-652.

14. Seidel S, Hartl T, Weber M, et al. PAMINA Study Group. Quality of sleep, fatigue and daytime sleepiness in migraine - a controlled study. Cephalalgia 2009;29:662-669.

15. Bertolazi NA. Tradução, adaptação cultural evalidação de 2 instrumentos de avaliação do sono: escala de sonolência de Epworth e Index de qualidade de sono de Pittsburgh [dissertation]. Universidade do Rio Grande do Sul, 2008.

16. Maluf TPG. Avaliação de sintomas de depressão e ansiedade em uma amostra de familiares de usuários de drogas que freqüentaram grupos de orientação familiar assistencial para dependentes químicos [dissertation]. Universidade Federal de São Paulo, 2002.

17. Gorenstein C,Andrade L.Inventário de depressão de Beck: propriedades psicométricas da versão em português. Rev Psiq Clin 1998;25:245-250.

18. Carneiro LM. Prevalência da cefaléia e suas consequências na qualidade de vida de motoristas de uma empresa de transporte coletivo urbano [dissertation]. Universidade Federal do Rio de Janeiro, 2005

19. Watt T, Groenvold M, Bjorner JB, Noerholm V, Rasmussen NA, Bech P. Fatigue in the Danish general population. Influence of sociodemographic factors and disease.J Epidemiol Community Health 2000;54:827-833. 